\title{
Jelly Dosage Form
}

National Cancer Institute

\section{Source}

National Cancer Institute. Jelly Dosage Form. NCI Thesaurus. Code C42948.

A semi-solid composed of suspensions of active and/or inert ingredient(s) in any type of highly viscous material, including gelatin or gel. The structural matrix of the jelly contains high levels of liquid. 